\title{
REGULARIZAÇÃO FUNDIÁRIA URBANA: PRETENSOS CONTRIBUTOS PARA REGULAMENTAÇÃO DA LEI FEDERAL N. 13.465/2017 E PARA A CONSTRUÇÃO DO PLANO DIRETOR DA CIDADE DO RIO DE JANEIRO $2021^{1}$
}

\author{
URBAN LAND REGULARIZATION: ALLEGED CONTRIBUTIONS TO THE REGULATION OF FEDERAL LAW NO. \\ 13.465/2017 AND FOR THE CONSTRUCTION OF THE MASTER PLAN OF THE CITY OF RIO DE JANEIRO 2021
}

\section{RESUMO}

A Lei Federal n. 13.465/2017 expressamente dispensa a intervenção do legislador local para a aplicabilidade imediata de seus preceitos, tornando despicienda em tese a atuação do legislador local. Ocorre que a lei federal traça normas gerais (i) cujas especificidades, em matéria de regularização fundiária para a população de baixa renda, já estão disciplinadas pelo parlamentar municipal carioca e (ii) cujas potencialidades, em matéria de regularização fundiária para a população de média e alta renda, podem ser exploradas diante das especificidades locais e dos princípios constitucionais de direito urbanístico que o informam, de modo que torna sua regulamentação local, por lei formal, um valioso instrumento de Política Urbana. A regulamentação municipal da nova lei federal sobre regularização fundiária urbana passa a ser um desafio também para que (i) o planejamento urbano ex ante não seja convertido em convalidação da ilegalidade urbana ex post e (ii) se promova uma regularização fundiária urbana sustentável capaz de gerar uma cidade supostamente menos iníqua e desigual, já que sua aplicação acrítica tende a provocar concentração fundiária, o que concorreria justamente para o quadro fático oposto ao que dela se espera, e (iii) se promova a mudança do status quo ante e não sua mera legitimação estatal. Por outro lado, nada obsta que desde logo se verifique como o anteprojeto de novo Plano Diretor da Cidade do Rio de Janeiro deve cuidar do tema da regularização fundiária urbana, diante das diretrizes gerais ditadas pelo marco regulatório nacional.

Palavras-chave: Direito da Cidade. Regularização Fundiária Urbana. Plano Diretor. Estatuto da Cidade.

\section{ABSTRACT}

Federal Law no. 13,465 / 2017 expressly dispenses the intervention of the local legislature for the immediate applicability of its precepts, making the performance of the local legislator negligible. It happens that the federal law outlines general norms (i) whose specificities, regarding land regularization for the low income population, are already disciplined by the municipal parliamentary from Rio de Janeiro and (i) whose potential, regarding land regularization for the middle and high income population, can be exploited in view of the local specificities and constitutional principles of urban law that inform it, so that its local regulation, by formal law, a valuable instrument of urban policy. The municipal regulation of the new federal law on urban land regularization also becomes a challenge so that (i) ex ante urban planning is not converted into ex post urban disorder regulation and (ii) promotes sustainable urban land regulation that generates a city supposedly less iniquitous and unequal, since its uncritical application tends to generate land concentration, which would concur precisely for the factual framework opposite to what is expected of it, and (iii) promote the change of the status quo ante and not its mere state legitimation. On the other hand, there is nothing to prevent the preliminary draft of the new Master Plan of the City of Rio de Janeiro from addressing the issue of urban land regularization, given the general guidelines dictated by the national regulatory framework.
Arícia Fernandes Correia ${ }^{a}$

${ }^{a}$ Universidade do Estado do Rio de Janeiro (UERJ), Rio de Janeiro, RJ, Brasil

DOI: $10.12957 /$ geouerj.2020.47270

Correpondência: ariciacorreia@oi.com.br

Recebido em: 12 set. 2019

Revisado em: 21 out. 2019

Aceito em: 12 dez. 2019

Keywords: City Law. Urban Land Regularization. City Master Plan

${ }^{1}$ Este artigo foi inspirado em reuniões realizadas com técnicos da Secretaria Municipal de Urbanismo encarregados da elaboração do Projeto de Lei do novo Plano Diretor da Cidade do Rio de Janeiro para 2021 e em virtude das discussões acerca do tema travadas em duas ocasiões: os seminários Revisão do Plano Diretor da Cidade do Rio de Janeiro e Plano Diretor e Efetividade, organizados, respectivamente, pela Comissão de Direito Urbanístico OAB/Barra e pela Comissão de Dir eito Municipal OAB/RJ, todos no primeiro semestre de 2019, constituindo uma versão resumida do artigo "Regularização Fundiária Urbana: pretensos contributos para regulamentação da Lei Federal n. 13.465/2017 e para a construção do Plano Diretor da Cidade do Rio de Janeiro 2021 e do Plano Integrado de Desenvolvimento da Região Metropolitana Fluminense. 


\section{INTRODUÇÃO}

O tema da questão fundiária mal resolvida no Brasil não é novo. Era irrelevante antes da chegada dos portugueses. Para dominar, porém, é preciso marcar o território, defendê-lo, mapeá-lo e, de preferência, registrá-lo. Parece simples, mas nem o Google Earth é capaz de modernizar um sistema registrário baseado em descrições de confrontantes e de coordenadas geográficas que apontam os limites dos imóveis constantes de milimétricos memoriais descritivos. A obrigação legislativa de georreferenciamento dos imóveis tampouco fez superar tais exigências. E, a despeito de tanta pretensa precisão, fato é que o tamanho geográfico do Brasil é bem díspar daquele que consta dos Cartórios de Registros de Imóveis ...

A secular irregularidade urbanístico-fundiária brasileira, por sua vez, contribui para esse descasamento entre as terras registradas em cartório e seus titulares e aqueles que efetivamente a ocupam.

Além disso, segundo o Banco Mundial, provavelmente inspirado no ideário dessottiano (DE SOTO, 2001), haveria um significativo potencial econômico no valor das terras brasileiras, principalmente onde se localizam os assentamentos populares (VIANA, 2018) - e isso sem falar em suas riquezas subterrâneas.

O atual marco regulatório nacional da regularização fundiária no Brasil seria um dos resultados desse diagnóstico de sub-aproveitamento econômico do valor das terras no Brasil, o que parece caricato e paradoxal diante de um passado de colonização de exploração de riquezas naturais extraíveis da terra: o pau-brasil, o café, o algodão, as minas de ouro ... Agora a grande riqueza passível de "exportação" seria a própria terra, o próprio Brasil. Algo parecido com a financeirização das cidades pelo "empreendedorismo urbano", de que trata Harvey (2006; 2010), alçado ao plano nacional, em matéria de dimensões geográficas, e à órbita internacional, se levada em conta a possibilidade de especulação imobiliária por estrangeiros, pessoas físicas ou mesmo organismos internacionais e entes soberanos.

Nenhuma dessas constatações surge assim à toa. Têm estreita relação com o histórico da colonização brasileira e do processo de concentração fundiária que sempre o caracterizou. E que talvez expliquem a mantença durante séculos da disputa entre posse e propriedade, a qual remonta às discussões doutrinárias entre Savigny e lhering. (TORRES, 2007; MENDONÇA, 2016) De toda forma, a despeito da autonomia da posse com o código civil do início do século XXI, ainda se considera irregular - porquanto suscetível de regularização fundiária - aquilo que a posse já resolveria per se, com seu direito da favela. (MAGALHÃES, 2006)

Resolveria, porém, prescindindo de escritura pública, registrada em cartório. A regularização fundiária, neste sentido, escritura não só o imóvel, mas o próprio território brasileiro. Em termos capitalistas, valoriza o ativo. Juridicamente, garante segurança jurídica mais acentuada ao ocupante, ainda que seja da posse. E é a única forma de transferência, se for da propriedade. Passa o Brasil a limpo no Cartório ... (Mas e na Constituição, também ?) E como já não se presumem necessariamente públicas as terras devolutas por falta 
de registro, haja Geografia e mapas que auxiliem o Direito e a aplicação da Lei de Registros Públicos e que não desprezem planejamentos urbanos idealizados em Planos Diretores que acabam se tornando ineficazes do ponto de vista social ...

Como prevaleceu no Brasil uma história de ocupação latifundiária, a bandeira da regularização fundiária foi bradada inicialmente pelos movimentos populares, daqueles que foram historicamente excluídos do mercado formal de terras, elitizado desde as sesmarias, passando pela Lei de Terras de 1850, chegando a um novo código civil que levou quase um século para se adaptar aos novos tempos e por uma visão plena de regularização urbanístico-ambiental e fundiária trazida pela Lei do Minha Casa, Minha Vida. Espera-se que a Lei Federal n. 13.465/2017, com sua aparente lógica proprietária, não represente um retrocesso em relação à autonomia da posse que tanto tempo se levou para conquistar e não venha titular, para especular, ao invés de garantir pelo um dos elementos da moradia adequada que é a segurança da posse.

\section{Regularização Fundiária como diretriz da Política Urbana}

Uma das diretrizes básicas da Política Urbana é a regularização fundiária urbana. Trata-se de processo extremamente lento, complexo e formal, com gargalos crônicos que vão do cadastro socioeconômico ao longo do tempo cambiante dos ocupantes à análise topográfica acidentada do solo urbano; do desenho de planos neófitos de alinhamento e parcelamento de ocupações autoconstruídas e não planejadas às vetustas estruturas registrárias luso-brasileiras; da cultura do ilegal, e daí à do regular, por que não para todos ?

A complexidade da gestão fundiária no Brasil se explica, também, pelos inúmeros procedimentos formais constituídos justamente para evitar possíveis fraudes e pela superlativa ocupação "irregular" do espaço, menos por desejo próprio do que por força das próprias circunstâncias históricas do processo de urbanização das cidades brasileiras: concentração fundiária nas mãos de poucos, exclusão social de muitos, alto valor da terra urbana e mobilidade metropolitana precária, entre outras mazelas estruturais.

O princípio da continuidade registrária, por exemplo, impõe uma rigidez que muitas vezes não acompanha a dinâmica da realidade urbana, mas que é fundamental para a proteção da boa fé de terceiros, gerando um permanente descompasso entre o registrado formalmente e o por muitas vezes transacionado informalmente. De outro turno, o excesso de zelo ou a visão ainda liberal - e absoluta - do direito de propriedade importa entraves a sua funcionalização, à percepção de que a garantia do direito à moradia adequada, aí englobados todos os elementos que o consagram internacionalmente como direito humano, antes realiza do que banaliza o direito à cidade. 
Segundo Holston (1993, p. 71), essas formalidades excessivas, aliadas ao sistema privado, complexo e frequentemente corrompido de gestão do cadastro de imóveis pelos cartórios no Brasil, sem falar no histórico latifundiário da ocupação brasileira, contribuíram para endossar a apropriação bastante desigual do solo, quase sempre beneficiando a concentração fundiária da propriedade nas mãos de alguns poucos beneficiados.

Por outro lado, para o mesmo Holston (2013), gerar a irregularidade urbanística teria se tornado, para a população de baixa renda, uma estratégia proposital de acionamento da máquina estatal da regularização fundiária, num círculo permanente de retroalimentação. Um diagnóstico factível talvez para alguns grupos de pressão, mas muitas vezes equivocado em relação àqueles que há quase um século se mantêm por sucessivas gerações nas mesmas comunidades, menos por falta de oportunidades, do que por escolhas convictas de manutenção de seus laços existenciais, para os quais a luta pela regularização fundiária não seria uma moeda de troca, mas a conquista de um direito histórico, "proporcionando aos seus ocupantes muito mais do que um título a ser registrado, mas, sobretudo, a tutela da dignidade sob várias vertentes da existência". (FRANCO, 2015, p. 636)

De toda forma, a demanda por regularização fundiária no Brasil de fato se deu a partir dos movimentos populares, se intensificou com a constituinte de 1988 - e a vitoriosa adoção de um Capítulo II dedicado à Política Urbana (ainda que no Título VII - Da Ordem Econômica e Financeira) - e cresceu a partir da criação das zonas de especial interesse social, cuja delimitação territorial, por lei, permitiria a adoção de parâmetros urbanísticos mais flexíveis para aqueles que autoconstruíram suas casas e lares à margem das leis de uso e ocupação do solo do Estado, de parcelamento do solo urbano e dos códigos de obras, sem falar no direito ao endereço enquanto "certidão de nascimento de cidadania", na expressão de Ricardo Almeida (2015).

Não foi e nem é diferente na cidade do Rio de Janeiro, cujas demandas iniciais de regularização urbanística e fundiária teriam partido antes dos loteamentos irregulares e clandestinos da zona oeste até do que das favelas do centro da cidade, bairro onde nascera aquela que teria sido a primeira favela carioca: o Morro da Providência. (ABREU, 1983)

As legislações locais sobre regularização urbanística e fundiária vieram como leis extravagantes ou no bojo dos Planos Diretores da Cidade, desde que se tornara uma das diretrizes obrigatórias da Política Urbana. Somente em 2009, a Lei do Minha Casa, Minha Vida sistematizou a matéria em seu Capítulo 3, criando figuras como a demarcação urbanística e a legitimação da posse, conversível, após cinco anos ininterruptos, se desprovida de desvio de finalidade superveniente que desse ensejo a sua cassação, em propriedade, uma espécie de "usucapião administrativa", que Ricardo Lira (1997) defendera mais de duas décadas antes de sua positivação. 
Antes mesmo de completar sua maioridade, todavia, o Capítulo 3 da Lei Federal 11.079/2009 veio a ser integralmente revogado pela Medida Provisória n. 759/2016, posteriormente convertida na Lei Federal n. 13.465/2017, veiculada como a solução ideal para a desburocratização e a democratização do processo de regularização fundiária brasileira, por um lado, e acusada de mantença do sistema de concentração do mercado de terras nas mãos de poucos, de outro.

Já se teve a oportunidade de apontar a lógica proprietária e os atributos enviesados da regularização fundiária a partir do novo marco regulatório, principalmente em dois sentidos: no de sua restrição à faceta escriturária e naquele apontado por Santos e Cruz (2018), de possibilitar um desvirtuamento do planejamento urbano ex ante diante da possibilidade contínua de convalidação de irregularidade urbanística ex post, numa coletânea com artigos de professores e alunos do programa de pós-graduação em Direito da Universidade do Estado do Rio de Janeiro, da linha de pesquisa de Direito da Cidade. (CORREIA, 2018)

Também já se relatou o longo processo de urbanização e regularização das primeiras comunidades do Programa Favela-Bairro no âmbito da Cidade do Rio de Janeiro, Fernão Cardin e Parque Royal, em outro volume, cujas etapas duraram vinte e cinco anos entre o início das obras de urbanização e o das titulações de seus longevos moradores, bem como as virtuais benesses passíveis de aproveitamento pela Municipalidade do novo marco regulatório urbano brasileiro. (CORREIA, 2017)

Neste estudo, partindo-se da presunção de constitucionalidade das leis e do indeferimento de medidas liminares positivas nas três ações diretas de inconstitucionalidade que foram movidas em face da Lei Federal n. 13.465/2017 - ADI n. 5.771, ajuizada pelo Ministério Público Federal, ADI n. 5.787, proposta pelo Partido dos Trabalhadores e ADI n. 5.883, cujo autor é o Instituto dos Arquitetos do Brasil -, estudam-se (i) os limites e as possibilidades de regulamentação da matéria por lei local e, de outro turno, (ii) as imposições de incorporação de seus conceitos ao vindouro Plano Diretor da Cidade do Rio de Janeiro, pretensamente em 2021, nossa amostra-Brasil de potencial aplicabilidade do novo marco regulatório da regularização fundiária urbana em matéria de normas diretivas urbanas.

Um pouco da História da Regularização Urbanística e Fundiária na Cidade do Rio de Janeiro

A Cidade do Rio de Janeiro já promovia regularização de interesse social, para a população predominantemente de baixa renda, há décadas: primeiro em relação aos loteamentos irregulares e clandestinos inscritos no Núcleo de Loteamentos do Município do Rio de Janeiro, apenas através da regularização urbanística e fundiária do loteamento em si e da elaboração de seu PAA (Plano Aprovado de Arruamento), seu PAL (Plano Aprovado de Loteamento) e da nomeação de seus logradouros, ficando a titulação dos proprietários/possuidores dos lotes (conversão de promessas de compra e venda, 
acompanhadas das respectivas provas de quitação, em escrituras definitivas, ações de usucapião e outros instrumentos) sob a responsabilidade dos interessados, que recorriam na maioria das vezes à Defensoria Pública; depois em relação aos conjuntos habitacionais construídos ou viabilizados através da Prefeitura da Cidade do Rio de Janeiro; e, somente mais tarde, via regularização fundiária plena: urbanística e fundiária completa, incluindo a titulação dos lotes individualizados, em favelas, através da hoje Coordenadoria de Regularização Urbanística e Fundiária da atual Subsecretaria Municipal de Habitação da Secretaria Municipal de Infraestrutura e Habitação da Cidade do Rio de Janeiro.

O ordenamento jurídico local, seja via Lei Orgânica do Município do Rio de Janeiro, Plano Diretor e legislação local extravagante, já admitia a regularização urbanística e fundiária de assentamentos populares e loteamentos populares irregulares e clandestinos ocupados predominantemente pela população de baixa renda, ainda mais diante da proliferação de leis de definição de Áreas de Especial Interesse Social (AEIS) (TRESSEB, 2018), imprescindíveis à fixação de parâmetros urbanísticos e edilícios mais flexíveis do que os do resto da cidade.

O Estado do Rio de Janeiro, através do Instituto de Terras do Estado do Rio de Janeiro (ITERJ) e da Companhia Estadual de Habitação (CEABH), também se dedicaram historicamente ao tema da regularização urbanística e fundiária em inúmeras comunidades do território fluminense, aquele voltado à regularização de assentamentos populares e esta à construção de unidades habitacionais, todos para a população de baixa renda.

Decerto que o trabalho restou incrementado com a Lei Federal n. 11.977/2009, de fundamental relevância para diversos processos de regularização que se encontravam em andamento, de que o do subbairro Barcellos da Rocinha seria o mais emblemático. (SOARES, 2014)

Prevaleciam, porém, as titulações com concessões de direito real de uso, pelo menos no âmbito do Município do Rio de Janeiro, e, a despeito da inovação legislativa, só foi possível a entrega de termos de concessão de domínio útil no caso de Parque Royal, uma vez que o Município do Rio de Janeiro era foreiro à União e não lograra nem a transferência do domínio direto da área, com a consolidação da propriedade plena, nem a delegação de poderes para a legitimação fundiária dos ocupantes em nome da União, a despeito de incessantes tentativas neste sentido, de modo a poder se valer da legitimação fundiária. (CORREIA, 2017)

Em relação à regularização de interesse específico, ou, dito de outro modo, no que tange à população de média e alta renda, não havia uma tradição de utilização de novos padrões de parcelamento por lei própria, díspares em relação ao resto da cidade, mas, tão somente, de construção, mediante cobranças de contrapartidas vulgarmente conhecidas como "mais-valias". De toda sorte, institutos do Estatuto da Cidade, como as operações urbanas consorciadas, assim como a própria outorga onerosa do direito de construir, já 
permitiam a flexibilização de parâmetros urbanísticos e edilícios em porções do território municipal não necessariamente ocupados por população de baixa renda, exigindo-se, sempre, porém, lei específica prévia que tratasse do tema.

Mais ou menos normalizada, a regularização fundiária, seja de interesse social, seja de interesse específico, recebeu novas normas gerais.

A Medida Provisória n. 759/2016, convertida na Lei Federal n. 13.465/2017, passou a imprimir dois principais desafios ao legislador local carioca: (1aㅡ) o de sua regulamentação, por lei ou regulamento próprio e (2ํㅡ) o de sua compatibilização, se for o caso, ao atual e também ao vindouro Plano Diretor de Desenvolvimento Sustentável da Cidade do Rio de Janeiro.

Valer-se-á, como metodologia, do tipo teórico-dogmática, do mapeamento normativo da legislação urbanística carioca em matéria de regularização urbanística e fundiária urbana em cotejo com o atual Plano Diretor Carioca, o novo marco regulatório urbano nacional, a Lei Federal n. 13.465/2017, e, na modalidade empírica, de levantamento, mediante entrevistas com os principais atores e instituições envolvidos nos processos de regularização urbanística e fundiária fluminenses e cariocas - representantes do Executivo Estadual e Municipal, da Defensoria Pública e do Ministério Público do Estado do Rio de Janeiro, da Procuradoria Geral do Município e das Comunidades Cariocas ${ }^{2}$-, e, por fim, numa proposta sintéticonormativa, de sugestões em relação ao tema da regularização fundiária urbana hoje, de sua possível regulamentação local e da legislação orgânica amanhã.

Antes dos desafios propostos, é mister compreender a divisão constitucional de competências acerca da matéria e alguns conceitos básicos veiculados pelo novo marco regulatório da regularização fundiária no Brasil, com recorte específico na modalidade urbana: a Lei Federal n. 13.465/2017 e o Decreto Federal n. $9.310 / 2018$

Divisão de Competências entre União e Municípios em Matéria Urbanística

\footnotetext{
2 As perguntas foram formuladas por WhatsApp com apenas três dias de antecedência para o fechamento deste artigo aos representantes da área em suas instituições: titulares de órgãos especializados em urbanismo, chefias de órgãos de regularização fundiária, advogados públicos que atuam ou produzem sobre a temática e membros de associações de moradores de comunidades cariocas. O questionário apresentou três perguntas comuns - (i) Quais seriam os pontos positivos e negativos que apontaria na Lei Federal n. 13.465/2017 ? (ii) Para uma regulamentação da matéria por lei municipal, quais seriam as suas propostas ? e (iii) 0 que gostaria de acrescentar ao tema ? - e pelo menos duas perguntas específicas, de acordo com o perfil da instituição/comunidade ou do próprio entrevistado. Responderam aos questionamentos: pelo ITERJ, a Presidente, Cláudia Franco; pela Procuradoria Geral do Município do Rio de Janeiro, os Procuradores Luiz Roberto da Mata e Fernanda Lousada, ambos com atuação pretérita e presente, respectivamente, na área de consultoria jurídica da Secretaria Municipal de Urbanismo; pela Defensoria Pública, a Titular do Núcleo de Terras, Maria Júlia Miranda, e, representando as comunidades cariocas, o Presidente da Associação de Moradores da Rocinha, André Gosi. A todos, o agradecimento penhorado pela contribuição.
} 
Segundo a Constituição, à União compete instituir diretrizes para o desenvolvimento urbano, inclusive habitação, saneamento básico e transportes urbanos e elaborar e executar planos nacionais e regionais de ordenação do território e de desenvolvimento econômico e social; legislar privativamente sobre certas matérias; bem como exercer uma série de competências em comum com os demais entes federativos que envolvem políticas urbanas, assim como legislar sobre normas gerais de direito urbanístico, cabendo aos Estados, Distrito Federal e Municípios suplementar a legislação federal e, estes, também a estadual, no que couber, na forma dos artigos 24, inciso I e $\S \S$ c/c artigo 30, incisos I e II, da Lei Maior.

Trata-se, pois, de competência concorrente pela qual à União cabe elaborar as normas gerais, sem prejuízo da competência municipal própria para disciplinar o interesse local, suplementar a legislação federal no que couber, promover o adequado ordenamento territorial, mediante planejamento e controle do uso, do parcelamento e da ocupação do solo urbano e para desenvolver a Política Urbana mediante pleno desenvolvimento local, com fundamento nas funções sociais da cidade e no bem estar de seus habitantes, entre outras competências que se inferem de sua autonomia federativa. A propósito, José Afonso da Silva (2010, p. 49) de há muito já lecionava que:

\footnotetext{
Já o planejamento urbanístico local encontra seu fundamento no art. 30, VIII, CRFB/88. Aí se conhece a competência do Município para promover, no que couber, adequado ordenamento territorial, mediante planejamento e controle do uso, do parcelamento e da ocupação do solo urbano. Isso não é competência suplementar, não. É competência própria, exclusiva, que não comporta interferência nem da União nem do Estado. (grifos nossos)
}

Há também a competência do Município para proteger o patrimônio cultural, material e imaterial, da Cidade, para garantir um meio ambiente sadio e equilibrado que gere cidades sustentáveis, para as presentes e futuras gerações, e para gerir seus bens, como corolário de sua autonomia administrativa, principalmente no que diz respeito à função social da propriedade pública. (ROCHA, 2005; MARRARA, 2007; MARQUES NETO, 2009; BAPTISTA, 2017)

O desafio do intérprete é o de harmonizar as normas efetivamente gerais de direito urbanístico de competência da União, fixadas, com a legislação municipal que diz respeito ao interesse local, ao adequado ordenamento territorial e ao desenvolvimento das funções sociais da Cidade.

No caso do ordenamento jurídico carioca, a regularização fundiária plena - a que exige prévia urbanização da área a ser regularizada e que alia a faceta urbanístico-ambiental e sociocultural à fundiária da regularização - é uma das diretrizes do planejamento urbano estabelecida no Estatuto da Cidade e, também, no Plano Diretor de Desenvolvimento Urbano Sustentável do Município do Rio de Janeiro, aprovado pela Lei Complementar Municipal n. 111/2011. 
Além disso, depende a regularização fundiária de interesse local de prévia delimitação da área passível de regularização como Área de Especial Interesse Social, na forma do artigo 70, inciso I, alínea "a", do Plano Diretor Carioca. Neste sentido, a despeito da expressa dispensa pelo legislador federal, as AEIS cariocas ainda são imprescindíveis aos processos de regularização urbana locais, porquanto imponíveis pelo legislador diretor.

Em outras hipóteses, em caso de conflito, na antinomia entre a lei nacional e o direito local, vencerá a competência municipal, caso a norma geral, descendo à minúcia, invada seu âmbito de competência exclusiva. Trata-se de exercício exegético que não envolve questão de hierarquia normativa, mas de "campo espacial" de competências federativas. Em sendo, porém, a lei federal veiculadora de norma efetivamente geral, cumpre ao legislador local se curvar. E obedecer. Faz parte do jogo (rectius, pacto) federativo.

\section{Novo Marco Regulatório da Regularização Fundiária Urbana: conceitos básicos}

A Lei Federal n. 13.465/2017 é acusada de trazer à baila a faceta estritamente dominial da regularização fundiária urbana, descurando de seus aspectos urbanísticos e socioambientais.

Segundo a dicção legal, os núcleos urbanos informais são formados por ocupações clandestinas ou irregulares do ponto de vista fundiário, onde resida população de baixa, média e alta renda, nos quais possam ser dispensadas exigências da legislação de uso, ocupação e parcelamento do solo urbano.

Para serem tidos por consolidados, devem ser de difícil reversão, considerados o tempo da ocupação, a natureza das edificações, a localização das vias de circulação e a presença de equipamentos públicos, entre outras circunstâncias a serem avaliadas pelo Município, o que, portanto, pode ser objeto de disciplina normativa local, como, por exemplo, a exigência de estudos de impacto urbanístico e ambiental e a criação de medidas de compensação ambiental que revertam a favor da própria área regularizada. Além disso, não podem possuir unidades imobiliárias de área superior à fração mínima de parcelamento prevista na Lei no 5.868, de 12 de dezembro de 1972, que, no caso, do Rio de Janeiro, é de dois hectares (INCRA, 2019).

O novo marco regulatório pretende beneficiar não só os núcleos ocupados pela população de baixa renda, como também os de média e alta renda, uma vez que por toda a cidade e independentemente da capacidade econômica do possuidor ou proprietário da terra, há casos de irregularidade urbanística de natureza fundiária passíveis de atos de fiscalização de polícia urbanística e edilícia também, inclusive de demolição, e, por isso mesmo, ansiosos pela deflagração de mecanismos oficiais de convalidação.

Neste sentido, os núcleos urbanos informais passíveis de regularização são aqueles cuja irregularidade urbanística ou clandestinidade não permitiram que os respectivos ocupantes fossem titulados, apresentando 
duas modalidades: a regularização fundiária urbana de interesse social (Reurb-s) e a regularização fundiária urbana de interesse específico (Reurb-e): a primeira voltada para a população predominantemente de baixa renda, assim considerada aquela que ganha até cinco salários-mínimos, e a segunda, para as demais, por exclusão.

A Reurb-s conta com significativa legislação municipal carioca, diferentemente da Reurb-e, que somente veio a ser disciplinada, com outros nomes e apelidos, em momentos diversos e em áreas pontuais, jamais sob uma perspectiva de procedimentalização unívoca, para toda a cidade.

Observe-se que também a legislação federal tradicionalmente cuidou da regularização fundiária de ocupações populares; confiram-se alguns exemplos: da lei de desapropriação por interesse social até a lei da concessão de direito real de uso para fins de regularização fundiária, leis com previsão de aforamento de imóveis públicos federais aos demais entes federativos, entre os quais, os municípios, para fins de regularização fundiária de ocupações formadas prioritariamente por população de baixa renda, dispensa de autorização legislativa e licitação para regularização fundiária de imóveis públicos ocupados por população de baixa renda, usucapião especial urbana individual e coletiva, demarcação urbanística e legitimação da posse voltadas à regularização fundiária de interesse social, concessão de uso especial para fins de moradia, também voltada para a população de baixa renda e leis de isenção de custas do primeiro registro decorrente de regularização fundiária, pela presunção de hipossuficiência financeira de seus beneficiários.

O Estatuto da Cidade foi provido de instrumentos jurídicos que em algumas oportunidades permitem, mediante lei prévia, a flexibilização de padrões urbanísticos, sem especificar quem sejam os destinatários e podendo assim representar hipótese de Reurb-s conjugada com Reurb-e, numa interpretação sistemática dos diplomas legais.

Apenas a Lei Federal n. 11.977/2009 previu timidamente a figura da regularização de interesse específico, a Reurb-e, com esse nome peculiar, em caráter residual à de interesse social, sem lhe especificar os contornos.

A Lei Federal n. 13.465/2017 de certa forma se apropria dessa expertise com a convalidação de irregularidades urbanísticas praticadas pela população de baixa renda (a Reurb-s) e a aproveita para a disciplina da regularização fundiária de interesse específico (a Reurb-e), razão pela qual, a despeito da isonomia no que interessa, há uma diferenciação significativa em relação ao patrimônio, não sendo proibido à população de média e alta renda ser proprietária, usufrutuária ou concessionária de outros bens, como ocorre com aquela; enquanto lá se visa à garantia do direito à moradia, aqui se pretende apenas a regularização da posse/propriedade per se. 
Posta a possibilidade de regularização urbanística e fundiária de toda a cidade - e é como está na Lei Federal n. 13.465/2017 -, enormes se tornam os desafios de uma atuação impessoal e de cunho planificador por parte tanto do legislador local, quanto do gestor público.

\section{Desafios da Regulamentação Local da Lei Federal n. 13.465/2017}

A Lei Federal n. 13.465/2017 dispensa expressamente a legislação local para fins de promoção do processo de regularização fundiária urbana, tornando despicienda a ação intermediária do legislador local, ao estabelecer, em seu artigo 29, parágrafo único, que não impedirá a Reurb a inexistência de lei municipal específica que trate de posturas de interesse local aplicáveis a projetos de regularização fundiária urbana.

É um equívoco, todavia, entender que só ela versa sobre "Reurb" (regularização fundiária urbana) ou que é pioneira no tratamento da matéria, só porque Ihe deu esse apelido. Ela é o novo marco regulatório nacional, dotado de competência para a definição de normas gerais, mas isso não afasta a existência de normas locais com ela compatíveis ou que atuam num campo não exatamente suplementar, mas próprio. Cabe ao intérprete identificá-las e filtrá-las, passando-as no teste de constitucionalidade, à luz da divisão de competências federativas antes apontada, verificando quais sobrevivem, por competência, às normas gerais federais/nacionais, e quais não, por hierarquia normativa mesmo.

Pode-se afirmar que a municipalidade carioca já conta com legislação urbanística sistemática em matéria de Reurb-s, tendo havido apenas iniciativas pontuais em matéria de Reurb-e. E que nada obsta que se valha de instrumentos novos de regularização do novo marco legal, que melhor se afeiçoem às comunidades, por exemplo, nas quais pretenda atuar.

Neste sentido, a regulamentação local, por parte do Município do Rio de Janeiro, da Lei Federal n. 13.465/2017 exige dois exercícios exegéticos iniciais: (i) o da compatibilidade normativa da legislação urbanística local já existente com o novo arcabouço jurídico nacional em matéria de Reurb-s e (ii) o da utilização do espaço de autonomia legislativa local para a disciplina da Reurb-e.

Dentre os principais desafios dessa regulamentação estão: (i) o respeito ao planejamento urbano, seja impedindo que a regularização ex post substitua a licença para lotear, desmembrar ou remembrar ex ante, seja pela delimitação prévia genérica e abstrata dos critérios de definição dos núcleos urbanos informais (por quiçá regiões da cidade ou por classificação temática de irregularidades passíveis de convalidação) e não de forma casuística, sendo dotados, portanto, de definição apriorística dos parâmetros urbanísticos porventura afastados, por autorização expressa da norma geral (art. 11, § 1으, da Lei Federal n. 13.465/2917), caso seja possível, (ii) a divisão dos bônus urbanísticos entre todos que, para suportar as irregularidades urbanísticas, dividem os ônus de uma infraestrutura urbana que precisou ser incrementada às custas do Erário Municipal, 
para o qual, afinal, toda a Cidade contribui, (iii) a criação de mecanismos tais que garantam a sustentabilidade ambiental, econômica e social da regularização urbanística e fundiária da cidade, conjugada com (iv) novas formas de gestão do patrimônio público imobiliário municipal e (v) a criação de metodologias de estudos de impacto regulatório urbano, tanto na área urbanística quanto na ambiental.

\section{Iniciativa Privativa}

Antes, porém, de tratar das questões materiais, torna-se mister cuidar de um requisito formal de validade dessa regulamentação, qual seja, a iniciativa privativa do Chefe do Executivo para dispor acerca da matéria. Com efeito, o direito urbanístico, além de se tratar de matéria predominantemente de interesse local, em termos de regularização fundiária urbana, envolve a gestão do solo urbano e a criação de parâmetros mais flexíveis ou, com o novo marco regulatório, o afastamento - que não deve ser episódico e casuístico, mas genérico e apriorístico, o que exige lei formal - da legislação de parcelamento, uso e ocupação do solo urbano, matérias cujas disciplinas exigem a privatividade da iniciativa por parte da autoridade máxima municipal, vez que versam sobre tema típico dos planos diretores locais e do interesse local.

A Lei Orgânica do Município do Rio de Janeiro, em seu artigo 70, parágrafo único, inciso V, estabelece um rol de matérias próprias à roupagem de lei complementar e cuja iniciativa é privativa da autoridade executiva máxima municipal, entre as quais se encontram os planos diretores. Por outro lado, entre as normas que complementam, por assim dizer, os planos diretores se situam necessariamente a legislação de uso, ocupação e parcelamento do solo urbano.

Além disso, o processo de regularização urbanística e fundiária envolve conferir atribuições a diversos órgãos do Executivo Municipal - desde a Secretaria de Infraestrutura e Habitação até a Pasta de Urbanismo , de forma que deve ser da iniciativa exclusiva do Prefeito, sob pena de violação ao princípio da separação dos poderes, gerando vício formal de inconstitucionalidade.

Aliás, essa, entre outras razões, motivou o ajuizamento de Representação de Inconstitucionalidade em face da Lei Complementar n. 188/2018, perante o Tribunal de Justiça do Estado do Rio de Janeiro, no bojo do processo judicial n.: 0004161-87.2019.8.19.0000. ${ }^{3}$ No julgamento de agravo regimental (Agravo Regimental na Representação de Inconstitucionalidade no 0051844- 57.2018. 8.19.0000), reverteu-se a decisão que negara a suspensão cautelar da eficácia da lei impugnada.

\footnotetext{
${ }^{3}$ MPRJ ajuíza ação por inconstitucionalidade contra lei que altera regras de ocupação e edificação na cidade do Rio de Janeiro. Disponível em: https://www.mpri.mp.br/home/-/detalhe-noticia/visualizar/65318. Acesso em 16 Set. 2019.
} 
Na data de 19/09/2019, publicou-se o julgamento da ação, reputando inconstitucional o diploma legal, conforme se confere da ementa que a seguir se reproduz:

Representações Por Inconstitucionalidade. Lei Complementar № 188, de 11 de maio de 2018, promulgada pela Câmara Municipal, após veto do Prefeito do Rio de Janeiro. Altera dispositivos das LC 160 e 161, ambas de 19 de maio de 2016. Vício de Inconstitucionalidade formal e material. $\mathrm{O}$ ato impugnado, ao dispor sobre o loteamento do solo de quase todo o Município do Rio de Janeiro, interferiu no âmbito das atividades do Poder Executivo. O uso e parcelamento do solo são atividades administrativas, representativa de atos de gestão, exclusivos do Poder Executivo, no exercício de seu poder discricionário. Violação ao Princípio da Separação dos Poderes. Inconstitucionalidade orgânica formal, que se traduz na inobservância da regra de competência para edição do ato. Vício formal de iniciativa A lei questionada promoveu o ordenamento territorial, usurpou a função do chefe do Executivo e feriu a Constituição do Estado do Rio de Janeiro. As leis complementares 160/2015 e 161/2015, abrangiam, ao todo, 13 (treze) bairros. A LC 188/2018 estendeu sua aplicação a 162 (cento e sessenta e dois) bairros de todo o Rio de Janeiro, incluídas áreas de preservação ambiental e lotes sequer ocupados, o que seria um incentivo à especulação imobiliária de áreas dominadas por milícias, por exemplo. Como se não bastasse, foi editado sem qualquer estudo ou planejamento a lhe conferir um mínimo de legitimidade. Vício Material. PROCEDÊNCIA DAS REPRESENTAÇÕES POR INCONSTITUCIONALIDADE, COM EFICÁCIA EXTUNC.

Do ajuizamento da ação pelo órgão ministerial, inferem-se outros requisitos materiais que o Parquet reputa imprescindíveis à constitucionalidade de lei dessa natureza, a par do vício formal de iniciativa, como a necessidade de estudo prévio de impacto ambiental, o debate democrático e a necessidade de combate à ação de milicianos.

Nada obsta, todavia, que eventual lei local que cuide do tema - a despeito da dispensa pelo legislador federal - seja provida de normas-standard, passíveis de complementação pela via regulamentar. Não é novidade. As leis que criam as Áreas de Especial Interesse Social no Município do Rio de janeiro costumam ter normas que promovem uma espécie de "delegificação" da matéria para o administrador público, de forma que a minudência dos respectivos parâmetros urbanísticos e edilícios constam de decretos. Trata-se de técnica - a de delegação de poder regulamentar por parâmetros legais mínimos estipulados pelo legislador que institui a AEIS ao administrador público - autorizada pelo artigo 205 do Plano Diretor da Cidade, que também encontra guarida no poder regulamentar lato sensu do Chefe do Executivo, previsto no artigo 107, inciso IV c/c inc. VI, alínea "a", da LOMRJ, norma simétrica às previstas nas Constituições do Estado do Rio de Janeiro e da República e que não compromete a observância do princípio da reserva de lei formal, porque ela fixa os standards básicos que o regulamento apenas irá pormenorizar. ${ }^{4}$

\footnotetext{
${ }^{4}$ Confira-se farta legislação das AEISs cariocas, providas deste fenômeno, muitas das quais repristinadas pelo artigo 2으o do Decreto RIO $44.853 / 2018$, em que cada ato normativo regulamentava a lei de criação da respectiva AEIS e seus parâmetros urbanísticos e edilícios, mais ou menos homogêneos, que haviam sido uniformizados por um ato normativo único que reduzia o gabarito máximo de todas as comunidades da cidade a irreais dois gabaritos, o que os tornaria insuscetíveis de regularização. De toda forma, havia subjacente também um esforço de contenção de novas ocupações irregulares, embora historicamente vão. Esse talvez seja o maior desafio da política pública de regularização: ao invés de resolver, eternizar o problema se efetivamente não adotada uma nova política urbana a partir de então.
} 
Verificar-se-á que essa questão se torna inclusive menos relevante na Lei Federal n. 13.465/2017, na medida em que ela (i) considera desnecessária a criação de AEIS para fins de instauração de processos de regularização fundiária urbana e (ii) autoriza que os núcleos urbanos informais sejam definidos por ato unilateral do Chefe do Executivo, desde que obedecidos os requisitos mínimos fixados no marco regulatório federal e naqueles que porventura venham a ser acrescentados pelo legislador/regulamentador local, caso deseje.

\section{Compatibilidade com a Lei Federal, a Lei Orgânica do Município do Rio de Janeiro e o Plano Diretor}

A futura lei local de regulamentação da Lei Federal n. 13.465/2017 deve respeito não só às normas gerais do diploma federal/nacional, mas, também, à Lei Orgânica do Município do Rio de Janeiro e ao Plano Diretor Carioca, de modo que: (i) ao contrário do legislador federal, que as dispensam, deve prever a criação de Áreas de Especial Interesse Social; (ii) pode declinar da criação de Áreas de Especial Interesse Específico, embora devam estabelecer as condições de criação, por ato do Chefe do Executivo, de núcleos urbanos informais passíveis de regularização ocupados predominantemente por população de média e alta renda e (ii) diversamente do legislador federal, que dela prescinde, devem preservar a urbanização antes ou ao menos durante a regularização, mas nunca depois.

Além disso, o conceito de regularização fundiária adotado pelo legislador local também não pode ser primordialmente fundiário (e, neste sentido, voltado exclusivamente para a titulação), mas, também, urbanístico, tendo em vista o Capítulo VII - Política de Regularização Urbanística e Fundiária do Título IV - Das Políticas Públicas Setoriais da Lei Complementar n. 111/2011, que serve de baliza à atuação do legislador local em matéria de direito urbanístico, aliás conforme já decidido, em decorrência do julgamento do Recurso Extraordinário 607.940 - DF, pelo Supremo Tribunal Federal, por maioria, na fixação da seguinte tese:

Tema 348 de Repercussão Geral

Os municípios com mais de vinte mil habitantes e o Distrito Federal podem legislar sobre programas e projetos específicos de ordenamento do espaço urbano por meio de leis que sejam compatíveis com as diretrizes fixadas no plano diretor.

Observe-se que o legislador diretor, em seu artigo $7^{\circ}, \S 1^{\circ}$, inciso $\mathrm{II}$, também menciona exemplificadamente a utilização de títulos próprios ao processo de regularização fundiária, na medida em que cita instrumentos jurídicos do Estatuto da Cidade, como a concessão de direito real de uso (CDRU) e o direito de superfície, e, na legislação extravagante, o instituto da concessão de uso especial para fins de moradia, criada pela Medida Provisória n. 2.220/2001 e mantida em vigor até hoje em função do disposto na Emenda Constitucional n. 32/2001, e a legitimação de posse da Lei Federal n. 11.977/2009, então em vigor nesta parte, embora a Municipalidade Carioca tradicionalmente tenha se valido mormente de CDRUs em suas titulações, 
o que, de toda forma, também encontra abrigo no artigo 183, parágrafo único, do texto constitucional. Além disso, segundo o legislador orgânico, eventuais doações de bens públicos para fins de regularização fundiária - e, mutatis mutandis, de legitimação fundiária de bens públicos municipais - deverão contar com a prévia aquiescência expressa do Chefe do Executivo, nos moldes do artigo 237 do diploma orgânico municipal.

\section{Autonomia Local e Lei Municipal de Regularização Urbanística e Fundiária Urbana}

A autonomia local permite ao Município suplementar a legislação federal, no que couber, de modo que, em matéria de definição do conceito de núcleo urbano informal, deve-se respeitar as normas gerais federais, mas nada importa que se acrescentem regras próprias a essa definição, ainda mais quando se levam em conta suas especificidades locais. Com efeito, o artigo $11, \S 1^{\circ}$, da Lei Federal n. 13.465/2017, estabelece que, para fins da Reurb, os Municípios poderão dispensar as exigências relativas ao percentual e às dimensões de áreas destinadas ao uso público ou ao tamanho dos lotes regularizados, assim como a outros parâmetros urbanísticos e edilícios.

Também é na sua esfera de competências exclusivas que o Município disciplina o ordenamento territorial, a legislação de parcelamento, uso e ocupação do solo, de modo que é recomendável, se houver diagnóstico hábil para isso, que o legislador desde logo aponte, por área ou região da cidade, respeitadas as especificidades do território, quais parâmetros urbanísticos poderiam ser afastados, qual o mínimo de área pública se compadece de ser exigido/dispensado ou urbanística e ambientalmente compensado, caso seja possível realizar desde logo esta tarefa in abstrato. Um trabalho inequivocamente de parceria entre arquitetos e urbanistas, juristas e legisladores.

É recomendável, outrossim, que se estabeleçam, observado esse amplo diagnóstico do território municipal, em que a área de planejamento urbano da Secretaria Municipal de Urbanismo é especializada e a de Meio Ambiente e tantos outros órgãos e entidades também têm muito a contribuir, e o conceito de cidade que se pretenda consolidar, quais medidas de compensação urbanística e ambiental poderiam ser desde logo elencadas, ainda que apenas por exemplo, no texto legal.

Nada obsta, também, que se faça menção aos novos instrumentos jurídicos da regularização da legitimação fundiária de imóveis públicos e do direito de laje como possíveis títulos com os quais se coroam processos de regularização, na medida em que possuem, para o direito urbanístico, esta faceta instrumental e, para o direito civil, natureza jurídica de direitos reais, de competência privativa da União, de modo que não se os estará criando, apenas fazendo remissão às respectivas legislações. Seria muito tentador fixar os critérios da legitimação fundiária que não o foram pelo legislador federal, mas neste caso me parece que se estaria a usurpar sua função. 
Pairam dúvidas, todavia, quanto à constitucionalidade do instituto da legitimação fundiária de imóveis particulares cujos requisitos possam ser diversos - como o tempo ad minus de ocupação - daqueles fixados para a usucapião, pela mera aquiescência tácita do respectivo proprietário, sob pena de incorrer o administrador público municipal inadvertidamente numa desapropriação indireta.

Também em matéria de licitação dispensada para a aquisição de imóveis públicos no contexto de regularizações fundiárias de interesse especial, é mister respeitar a competência privativa da União para legislar sobre licitações, sem descurar da suplementar local. Até porque a forma de cálculo do imóvel público - se será só o valor do imóvel descontadas as benfeitorias ou se se abaterá também a valorização que elas tenham proporcionado ao imóvel, uma precificação difícil de ser feita a posteriori - é matéria de titularidade e gestão de bens públicos municipais, que, a rigor, se inseririam na órbita da competência local, podendo ser a norma entendida, nesta parte, como estritamente federal, o que facultaria ao parlamentar municipal fixar os critérios de determinação do valor do imóvel público municipal cuja venda afinal terá tido seu procedimento licitatório dispensado pelo legislador federal.

Isso não é uma inovação interpretativa do pacto federativo brasileiro. Em matéria de gestão de bens públicos no bojo da Lei de Licitações e Contratos, entendeu o Supremo Tribunal Federal, no julgamento da Ação Direta de Inconstitucionalidade n. 9.27-3, que o artigo 17 da Lei Federal n. 8.666/1993 (e alterações) seria estritamente aplicável à União e não aos Estados-membros, Distrito Federal e Municípios, que disciplinam a matéria por legislação própria.

Essa autonomia local também permite aos Municípios, em nome dos princípios urbanísticos já elencados - repartição dos ônus e bônus urbanísticos, função social da propriedade e da cidade e desenvolvimento urbano sustentável -, adotar regras próprias que: (i) autorizem a cobrança de contrapartida, na Reurb-E, pela mais-valia urbana apropriada privativamente por quem não respeitou o planejamento urbano, e, principalmente, os planos de loteamento de cada cidade, (ii) cobrança esta que pode ocorrer não só em (ii.i) pecúnia, mediante aporte, segundo o Plano Diretor, ao Fundo Municipal de Desenvolvimento Urbano (o qual, segundo entendimento fixado a partir de diligência oriunda do Tribunal de Contas do Município, corresponderia ao Fundo Municipal de Habitação), ou, também, aos Fundos Municipais de Habitação de Interesse Social ou de Meio Ambiente, mas, também, em (ii.ii) obrigações de fazer, como, por exemplo, num núcleo urbano informal híbrido, os ocupantes da Reurb-e serem responsáveis pelo custeio da Reurb-s, mediante termo de compromisso firmado entre as partes, atuando o Município como mediador; e (iii) prevejam, em adição, formas de compensação urbanísticas e ambientais pela regularização de interesse especifico.

Em tempos de consensualismo judicial e extrajudicial, também seria salutar prever na própria lei uma margem de negociação que permitisse ao Advogado Público celebrar acordos com os interessados, tentando 
mediar conflitos fundiários e, por um lado, observando o princípio da legalidade, e, por outro, os da razoabilidade/proporcionalidade já sopesados de antemão pelo próprio parlamentar municipal. Salutar também é a cooperação institucional dos órgãos da Defensoria Pública e do Ministério Público, de modo a legitimar democraticamente tais decisões.

A busca da regularização fundiária e da cidade sustentável passam também por mecanismos que coíbam: (i) a gentrificação, na regularização de interesse social; e (ii) a impunidade de loteadores irregulares e clandestinos, em qualquer modalidade.

Neste sentido, para coibir a gentrificação, a par da mantença das AEIS, sugere-se a proibição de novos remembramentos, a vedação ao desvio de finalidade do instituto, no que diga respeito a áreas notoriamente desprovidas de população preponderantemente de baixa renda, e a redução dos custos da regularização, neste caso, através de isenções fiscais de tributos imobiliários, como IPTU e ITBI, por legislação própria. (CORREIA, 2019, pp. 237-292)

A preferência pela obtenção da propriedade - e não exatamente pela garantia do direito à moradia de que se acusa o legislador federal é uma medida que, no exercício do poder legislativo municipal, poderia ser atenuada: (i) se fossem eleitos critérios de titulação que, em dependendo da área regularizada e do estoque de terras públicas disponível, hábeis à regulação indireta do preço dos alugueres, preferissem a segurança da posse, mesmo com a mantença da titularidade do bem nas mãos estatais, à da propriedade; (ii) se o projeto urbanístico fosse visto como a garantia de um plano local de desenvolvimento estruturante, uma espécie de plano diretor local, muito mais do que um simples elemento formal, que muitas das vezes somente reproduz o status quo, jamais pretende modificá-lo; (iii) se entre as possibilidades não propriamente de regularização, mas de garantia do direito à moradia, constasse também o da locação social, tudo (iv) sem prejuízo da utilização, por regra, da legitimação fundiária para as áreas carentes da Cidade menos cobiçadas pelo mercado. Em relação à Reurb-E, há que se (i) prever a desnecessidade de criação de Áreas de Especial Interesse Específico, salvo se assim o desejar o futuro legislador diretor; e (ii) respeitar a previsão de licitação dispensada posta pelo legislador federal, com as possíveis polêmicas ressalvas já alinhavadas.

A rigor, não há mapeamento da irregularidade urbanística na Reurb-E, principalmente em razão de sua clandestinidade, tal qual o há na Reurb-S por parte da Prefeitura da Cidade do Rio de Janeiro, cujas favelas são mapeadas em tempo real e cujos territórios estão devidamente delimitados no Sistema de Informações Urbanas (SIURB), um relevante instrumento de inteligência para a formulação da política urbana concebido pelo Instituto Pereira Passos e alimentado por diversos órgãos da Municipalidade Carioca.

Observe-se, outrossim, que tais medidas de "convalidação da irregularidade urbanística" não podem ser tomadas sem que: (i) se punam exemplarmente os loteadores irregulares e clandestinos; e (ii) se estabeleça 
uma data-marco, a despeito das ponderáveis críticas de Rolnik (2016), que separe o "estoque" de irregularidade urbanística da cidade, do modo de ocupação que se planeja para o futuro, tentando impedir que o processo de regularização urbana opere contínua, indefinida e universalmente, sob pena de se comprometer todo o planejamento urbano da cidade, o qual, a seu turno, também não deve se pretender mais real do que a realeza - ou muito menos do que a pobreza.

A previsão de parcerias com a Corregedoria de Justiça seria uma forma de estabelecer como norte a imprescindibilidade da colaboração cartorária para com os trabalhos de regularização urbana, de cujo registro dependem para serem concluídos. Também a aliança com o Instituto dos Arquitetos do Brasil poderia facilitar a elaboração de PALs, tanto quanto o permanente diálogo com Defensoria Pública, Ministério Público, órgãos patrimoniais da União e do Estado do Rio de Janeiro e, em especial, o ITERJ e a CEHAB, voltados para a garantia do direito à moradia para a população de baixa renda, cujos trabalhos muitas vezes dependem de iniciativas e legislações locais, sem falar na aliança com o Tribunal de Justiça em matéria de pacificação extrajudicial de conflitos fundiários, tarefa de que já vem se desincumbindo graças à iniciativa do Procurador do Estado Maurício Mota.

Há desafios extra legem a enfrentar também, já que de fato nem a prancheta de um arquiteto, como diria Henri Lefèbvre (2001), nem a pena de um jurista irão resolver as mazelas da cidade do Rio de Janeiro que remontam a antes mesmo de 1565 , ano de sua fundação...

No caso da Reurb-E, o desafio será a delimitação dos núcleos urbanos informais, uma vez que na Reurb$S$ eles, se não se confundem, ao menos devem se restringir aos limites geográficos das AEIS. Em se tratando de Reurb-S, não é necessário estudar Sociologia Urbana para compreender que a milícia agora não sobrevive apenas da venda de botijões de gás ou assinaturas de TVs a cabo, mas de um ativo muito mais valioso: a terra urbana. A financeirização do Brasil não é só dos grileiros rurais; cidade não tem tanto grilo quanto o meio rural, mas tem grileiro urbano, armado e perigoso, capaz de coibir a fiscalização mesmo se ela surpreendentemente puder acompanhar sua velocidade. Fato é que o ritmo da ilegalidade urbana é assaz superior ao da burocracia estatal, seja por naquela se tratar de uma estratégia de resistência dos próprios ocupantes, de que fala Holston (2013), seja porque nesta se garantem direitos, como contraditório, ampla defesa e devido processo legal, que loteadores irregulares e clandestinos criminosos negam de forma peremptória e, por vezes, fatal.

Interessante apontar, neste sentido, as principais sugestões dos entrevistados em relação à proposta de regulamentação local da Lei Federal n. 13.465/2017, nas suas próprias palavras:

Pergunta: Se o Município vier a regulamentar por lei própria, o que você acrescentaria na disciplina legal da matéria dentro da esfera de autonomia do ente local? 
Cláudia Franco, Presidente do ITERJ

Temos um gargalo no processamento da regularização fundiária que são os cartórios. Com todo respeito que tenho pela atividade cartorária brasileira, mas em certos casos a burocracia que se cria é demasiada, um contra senso a função social dos cartórios, bem como a necessidade de viabilizarmos o acesso ao direito se moradia com a segurança jurídica necessária. É direito, não é favor.

Portando, creio que deveríamos ter regras mais eficazes que descompliquem o processo.

Outra questão é estabelecer prazos curtos exequíveis de respostas a processamento. Tem que ter prazo para terminar, dar uma solução. É a vida das pessoas. A titulação trás dignidade . No Iterj nosso lema é regularizar para dignificar!

Luiz Roberto da Mata, Procurador do Município

Em relação ao que tradicionalmente se denomina ordenamento urbanístico e edilício, a Lei Federal de REURB não condiciona de forma alguma a regularização fundiária. Nada impede que o legislador municipal disponha sobre parâmetros mínimos mesmo para efeito de "REURB-S". Cabe aos próprios Municípios disporem sobre os parâmetros que eles irão dispensar, e em que medida. Um exemplo bem singelo seria uma norma municipal que em defesa da salubridade das ocupações dispusesse no sentido de que a regularização exige condições adequadas de iluminação, insolação e ventilação das edificações. Outro aspecto que abre espaço para a regulação pela lei local é a previsão na Lei Federal de regularização das ocupações não residenciais, parecendo relevante que a lei municipal cuide de não permitir atividades que possam comprometer a qualidade de vida dos moradores. Assim, para que as atividades não residenciais sejam regularizadas conjuntamente com as ocupações residenciais necessário que sejam atividades não poluentes. A Lei Federal de REURB prevê uma compensação ambiental quando aprovada uma "REURB-E", tocando ao legislador municipal dispor sobre o valor dessa compensação, com a respectiva fórmula de cálculo, bem como dispor sobre a destinação do montante arrecadado. Quando na "REURB-E" a ocupação regularizada atingir um bem público, o respectivo valor deve ser pago aos cofres públicos pelos beneficiários da titulação, devendo o Município dispor sobre a fórmula de cálculo do valor e condições de pagamento. (...) Importante ter em conta que no momento da aprovação de cada REURB o Poder Público pode fazer exigências de urbanização, de sorte que não necessariamente precisa estar na norma municipal tudo o que se considera desejável em termos de infraestrutura. (...) Quando a urbanização ficar a cargo do Poder Público o que se deve considerar é que ela será executada em conformidade com as possibilidades orçamentárias, concorrendo por recursos com todas as outras necessidades públicas ${ }^{5}$.

A titular do Núcleo de Terras da Defensoria Pública do Estado do Rio de Janeiro relata a imperiosidade de regulamentação da matéria.

Maria Júlia Miranda, Defensora Pública, Titular do Núcleo de Terras

Quais as principais demandas acerca do tema apresentadas pelas comunidades à Defensoria Pública do ERJ?

A principal demanda é pela titulação. Contudo, até o presente momento, a Prefeitura do Rio de Janeiro não adotou o procedimento administrativo da Lei 13465. Dessa forma, o NUTH tem feito a opção de obter o título através do ajuizamento da ação de usucapião coletiva.

Para André Maurício Gosi, da Associação de Moradores do Vidigal, a lei de regularização fundiária é de extrema relevância para a comunidade:

Arícia: O que você entende por Regularização Fundiária de uma comunidade? Você acha que ter um título de propriedade no Vidigal muda em alguma coisa a vida das pessoas?

André Vidigal: 1- assegura o nosso direito de permanecer no local sem ter que se preocupar com a remoção, hoje temos mais garantias com recursos jurídicos, que no passado não havia infelizmente. No caso do Vidigal tivemos ameaças de remoção nas décadas anteriores e graças a pastoral de favelas, advogados pagos com recursos da igreja católica, mobilização de associação de moradores foi garantido o direito de permanecer no local!

\footnotetext{
${ }^{5}$ Em breve a entrevista de Luiz Roberto da Mata será publicada na íntegra nas Colunas Urbanas do site do Núcleo de Estudos, Pesquisas e Extensão em Direito da Cidade: www.nepec-uerj.com.br.
} 
André Vidigal: O título de propriedade muda e muito, legitima a nossa permanência, mas infelizmente muitos moradores não têm. É um processo muito lento eu acho proposital o governo não comenta muito sobre esse assunto, principalmente o Vidigal!

A questão está longe de ser simples, mas se há um consenso é o de que mereça ser enfrentada, não só do ponto de vista legislativo, mas, principalmente, financeiro, com medidas de caráter redistributivo que a viabilizem, ouvidas as comunidades interessadas principalmente quanto à posição da demanda no seu ranking de prioridades existenciais.

Fernanda Lousada, Procuradora do Município do Rio de Janeiro

A consideração de cada parte da cidade, interagir com o Plano Diretor e demais planos municipais. Minudenciar prazos e procedimentos. Acho que deveria haver regulamentação da reurb junto com o estatuto. Os instrumentos e institutos deviam conversar mais, porque no caso concreto normalmente se precisa de mais de um deles para resolver a questão.

Com efeito, o artigo 2으, inciso XIV, da Lei Federal n. 10.257/2001 estabelece que a política urbana tem por objetivo ordenar o pleno desenvolvimento das funções sociais da cidade e da propriedade urbana, mediante diretrizes gerais, entre as quais, a de "regularização fundiária e urbanização de áreas ocupadas por população de baixa renda, mediante o estabelecimento de normas especiais de urbanização, uso e ocupação do solo e edificação, consideradas a situação socioeconômica da população e as normas ambientais." De outro turno, entre as demais diretrizes da Política Urbana traçadas no Estatuto da Cidade, estão também, segundo o artigo 46, incisos IX e XI, respectivamente, a justa distribuição dos benefícios e ônus decorrentes do processo de urbanização e a recuperação dos investimentos do Poder Público de que tenha resultado a valorização de imóveis urbanos.

Como o Plano Diretor da Cidade deve obedecer tais diretrizes, enquanto a Reurb-s deve garantir o direito à moradia e a regularização fundiária para a população de baixa renda como reflexo dessa política pública urbana inclusiva, a Reurb-e, ao gerar incremento no valor de imóveis, com uma política de regularização "apropriada" da população de baixa renda, não só pode como deve recuperar esse valor, ainda que seja sob a forma de uma contrapartida por essa regularização, realizando-se, assim, plenamente diretriz outra, qual seja, a da justa distribuição dos bônus e ônus decorrentes da urbanização.

Neste sentido, (i) impõe-se que seja cobrada contrapartida pelo Poder Público na Reurb-E, a exemplo das mais-valias cobradas em relação a imóveis individuais, sendo que agora o cálculo deverá levar em conta o valor não do metro quadrado do imóvel, mas da gleba, antes e depois de valorizada, por cada um dos proprietários dos lotes em que ela nunca fora dividida ou em que ela porventura irregularmente se desmembrou, bem como o tempo de irregularidade, embora essa previsão deva constar da lei própria, podendo o Plano Diretor apenas classificar irregularidades ou dividir o território em áreas mais ou menos homogêneas em que sejam verificados in abstrato os parâmetros suscetíveis de afastamento; e (ii) admite-se 
que ou sejam criadas novas Áreas de Especial de Interesse Específico (AREIS), as quais coincidam com os núcleos urbanos informais da Reurb-E ou que, no lugar de AEIS e AREIS, seja adotada, no novo Plano Diretor, a figura dos Núcleos Urbanos Informais, se a Municipalidade dispuser de um diagnóstico tal da irregularidade urbanística no território que lha permita mapeá-los desde logo ou, na impossibilidade de fazê-lo, adotar os critérios genéricos e abstratos de sua definição atenta às peculiaridades locais, evitando-se uma definição casuística e pessoal por mero ato do Chefe do Executivo, o que seria incompatível com o ordenamento territorial da cidade, o qual pressupõe planejamento urbano.

O título dedicado à regularização urbanística e fundiária de interesse social agora virará um Capítulo, com algumas regras comuns - como a própria definição do que seja núcleo urbano informal - e cujas Seções serão díspares: uma para a Reurb-S, gratuita por excelência e outra para a Reurb-E, onerosa sempre (ainda que pela via sempre malograda do ressarcimento...), presididas cada qual por lógicas diversas - aquela a posse/propriedade como meio de garantia do direito à moradia; esta do direito de propriedade tout court, sirva ao beneficiário como moradia ou não.

São lampejos de reflexões sobre o tema que ainda exigem o devido amadurecimento - e muito, muito diálogo com os experts na matéria e os diversos atores envolvidos e seus múltiplos interesses.

\section{CONCLUSÕES}

A Lei Federal n. 13.465/2017, apesar de dispensar expressamente a ação intermediária do legislador local, não a proíbe; antes, as atribuições impostas ao Município em matéria de traçado da Política Urbana, disciplina do interesse local, mormente no que diz respeito à ordenação do solo urbano, o exigem.

A tarefa, todavia, não é singela, porque importa estabelecer, com uma política pública de regularização, uma linha tênue entre a cidade que se quer ter e a cidade que se tem. Dito de outro modo, é preciso que a regularização do ontem não impeça o planejamento de um amanhã melhor, evitando-se que se coloque em xeque a atividade do planejamento urbano.

Afora isso, a regulamentação local permite que sejam aproveitadas as vantagens do novo marco regulatório nacional, que seja aprimorada - e planejada por áreas, por exemplo - a definição dos núcleos urbanos informais, que haja repartição de ônus e bônus urbanísticos entre regularização de interesse social e de interesse específico e que se aprimorem mecanismos de compensação urbanística e ambiental capazes de tornar as áreas regularizadas, além de sustentáveis, necessariamente melhores do que antes do processo de regularização. 
Diante do advento da Lei Federal n. 13.465/2017, é imprescindível que o novo Plano Diretor da Cidade da Cidade do Rio de Janeiro, de 2021, de que a regularização fundiária é uma das diretrizes principais, incorpore todas as suas potencialidades.

Trata-se de enormes desafios para a política urbana da Cidade e também da Região Metropolitana do Rio de Janeiro deste quinto inicial do século XXI. Há esperanças. Na resposta do representante da Associação de Moradores do Vidigal, uma das comunidades onde as diferenças sociais convivem de maneira mais harmônica do que em outras, uma resposta relativa à sustentabilidade econômica, cultural e social da regularização fundiária, que, em sua faceta urbanística, admitiu essa mistura, emociona:

Arícia: O que você acha da mistura de classes sociais no Vidigal, isso é considerado bom por todos? André: O Vidigal tem uma experiência muito positiva, eu costumo falar que conhecemos o mundo através dessa troca. Benefícios como empreendedorismo, turismo e cultura são o nosso pilar consolidado.

Nem precisava grifar.

\section{REFERÊNCIAS}

ABREU, Maurício. A evolução urbana do Rio de Janeiro. Rio de Janeiro: Prefeitura da Cidade do Rio de Janeiro, 1983.

ALFONSIN, Betânia. Cidade para Todos/Cidade para Todas - Vendo a Cidade através do Olhar das Mulheres. In: ALFONSIN, Betânia e FERNANDES, Edésio. (Orgs.) Direito Urbanístico: estudos brasileiros e internacionais. Del Rey: Belo Horizonte, 2006.

ALFONSIN, Bethânia. e FERNANDES, Edésio (Organizadores e co-autores) Direito à Moradia e Segurança da Posse no Estatuto da Cidade. Diretrizes, Instrumentos e Processos de Gestão. Belo Horizonte: Fórum, 2004.

SILVA, Ricardo Almeida da. Um endereço na cidade, Colunas Urbanas, Nepec, n. 2, Ano 1, Rio de Janeiro, 2019. Disponível em: www.uerj-nepec.com.br/colunasurbanas. Acesso em:

BAPTISTA, Patrícia. Problemas da perspectiva Civilista sobre o Regime Jurídico dos Bens Públicos. Revista da Faculdade de Direito da UERJ, n. 31, 2017.

BARBOSA, Miracy. (Re) Pensando a pesquisa jurídica. Belo Horizonte: Del Rey, 2006.

BRASIL. Instituto Nacional de Colonização e Reforma Agrária. Disponível em:

http://www.incra.gov.br/sites/default/files/uploads/estrutura-fundiaria/regularizacao-fundiaria/indices-

cadastrais/indices_basicos_2013_por_municipio.pdf Acesso em 16 Set. 2019.

CASTRO, Tânia. Postos de Orientação Urbanística e Social. Rio de Janeiro: Secretaria Municipal de Habitação, 1994.

CORRÊA, Cláudia Franco. Instrumentos de Regularização Fundiária nas Favelas. In: MELO, Marco Aurélio Bezerra de. e MELO, Fábio. (Orgs.) Direito Imobiliário: estudos em homenagem ao Professor Ricardo Pereira Lira. São Paulo: Atlas, 2015.

CORREIA, Arícia Fernandes. Advocacia Preventiva no período pós-regularização fundiária urbana: em busca do caráter redistributivo do tributo. In: GAZOLA, Patrícia Marques e CORREIA, Arícia Fernandes. (Coord.) Advocacia Pública Municipal do Século XXI: sua relevância no desenvolvimento dos Municípios Brasileiros. Rio de Janeiro, Multifoco, 2019, pp. 237-292.

CORREIA, Arícia Fernandes. Regularização Fundiária Urbana Plena: teoria, práxis e pesquisa sobre a regularização urbanística e fundiária brasileiras, em especial, da cidade do Rio de Janeiro. Belo Horizonte: Editar, 2017.

CORREIA, Arícia Fernandes. (Coord.) Regularização Fundiária Urbana Sustentável: pesquisa, teoria e prática sobre a Lei Federal no 13.465/2017. Belo Horizonte: Editar, 2018.

CORREIA, Arícia Fernandes. Moradia e Exclusão Social na Metrópole. Rio de Janeiro: Multifoco, 2016. 
CORREIA, Arícia Fernandes. e FARIAS, Talden. Licenciamento Urbanístico-Ambiental na Regularização Fundiária Sustentável: a possibilidade de fomento local ao uso de energia solar em assentamentos precários. Revista de Direito da Cidade - Vol. 7, №2, 2015. Disponível em: http://www.e-publicacoes.uerj.br/index.php/rdc/article/view/16955.

CORREIA, Arícia Fernandes. e FARIAS, Talden. Regionalismo como uma nova perspectiva para o Federalismo Brasileiro: o leading case relativo à Região Metropolitana do Rio de Janeiro. In: AIETA, Vânia. (Org.) Cadernos de Direito da Cidade. Série I. Rio de Janeiro: Lumen Juris, 2013.

DE SOTO, Hernando. O Mistério do Capital: Por que o Capitalismo Triunfa no Oeste e Falha em Toda a Parte. São Paulo: Record, 2001.

FARIAS, Talden. e CORREIA, Arícia Fernandes. Licenciamento Ambiental e Sustentabilidade no Meio Ambiente Urbano. In: SEABRA, Giovai. (Org.) Educação Ambiental: conceitos e aplicações. João Pessoa: UFPB, 2013.

FERNANDES, Edésio. Do Código Civil ao Estatuto da Cidade. Algumas notas sobre a trajetória do direito urbanístico no Brasil, Urbana, n. 30, p. 43-59, 2002.

GOUVÊA, Denise de Campos. e RIBEIRO, Sandra Bernardes. A Política Nacional de Regularização Fundiária - Programa Papel Passado - Avanços e Desafios. In: ALFONSIN, Betânia. E FERNANDES, Edésio (coord.). Direito à moradia adequada: o que é, para quem serve, como defender e efetivar. Belo Horizonte: Fórum, 2014.

HARVEY, David. O enigma do capital e as crises do capitalismo. Tradução de João Alexandre Perchanski. São Paulo: Boitempo, 2010.

HARVEY, David. A produção capitalista do espaço. São Paulo: Annablume, 2006.

HOLSTON. James. Cidadania Insurgente: disjunções da democracia e da modernidade no Brasil. Tradução de Claudio Carina. São Paulo: Companhia das Letras, 2013.

HOLSTON. James. Legalizando o ilegal: propriedade e usurpação no Brasil, Revista Brasileira de Ciências Sociais, n.21, p.68-89, 1993.

LEFEBVRE, Henri. Le droit a la ville. Trad. Rubens Frias. São Paulo: Centauro, 2001.

LIRA, Ricardo Pereira. Elementos de Direito Urbanístico. Rio de Janeiro: Renovar, 1997.

MAGALHÃES, Alex. O Direito das Favelas. Rio de Janeiro: Letra Capital, 2006.

MARRARA, Thiago. Bens Públicos, Domínio Urbano, Infraestruturas. Belo Horizonte, Fórum, 2007. MARQUES NETO, Floriano Azevedo. Bens Públicos: Função Social e Exploração Econômica. O Regime Jurídico das Utilidades Públicas. Belo Horizonte: Fórum, 2009.

MELO, Lígia. Direito à Moradia no Brasil: Política Urbana e Acesso por meio da Regularização Fundiária. Belo Horizonte: Fórum, 2010.

MENDONÇA, Rafael da Mota. Segurança da posse, consenso democrático e controle externo unilateral: avanços e retrocessos na história da ocupação do Horto Florestal, na cidade do Rio de Janeiro. Dissertação de Mestrado, Rio de Janeiro: UERJ, 2016.

SANTOS, Ângela Moulin Penalva. e CRUZ, Carlos Eduardo de Souza. Regularização Fundiária: de seu avanço institucional à reprodução crescente do problema que a originou. In:

SILVA, José Afonso da. Direito Urbanístico Brasileiro. São Paulo, Malheiros, 2010.

SOARES, Priscila. GONÇALVES, Rafael Soares et al. A regularização fundiária na favela da Rocinha: aprendizados e desafios. In: FERNANDES, Edésio e AFONSIN, Betânia. Direito à Moradia Adequada: o que é, para quem serve, como defender e efetivar. Belo Horizonte: Forum, 2014.

ROCHA, Silvio Luís Ferreira da. Função Social da Propriedade Pública. São Paulo: Malheiros, 2005.

ROLNIK, Raquel. Guerra dos Lugares: a colonização da terra e da moradia na era das finanças. São Paulo: Boitempo, 2016.

SABINO, Jamilson Lisboa. Curso de Formação e Atualização em Regularização Fundiária Urbana. Escola Brasileira de Administração Pública. Salvador, 2019. (informação verbal)

TORRES, Marcos Alcino Azevedo. Posse e Propriedade: um confronto em torno da função social. Rio de Janeiro: Lumen Juris, 2007.

UGEDA, Luiz. Direito Administrativo Geográfico. Rio de Janeiro: Instituto GeoDireito, 2017.

VALLADARES, Lícia. Da invenção da favela: do mito de origem à favela.com. Rio de Janeiro: FGV, 2005.

VASQUES, Pedro Henrique Ramos Padro. Regularização Fundiária em Unidades de Conservação de Proteção Integral no Estado do Rio de Janeiro: breve análise da atuação do executivo estadual frente a pequenos proprietários e grupos vulneráveis. In: CORREIA, Arícia Fernandes. (Coord.). Moradia e Exclusão Social na Metrópole. Rio de Janeiro: Multifoco, 2016. 
VIANNA, Alice Nohl. A Lei 13.465 de 2017 e o Mecanismo de Registro da Propriedade Urbana. In: CORREIA, Arícia Fernandes. (Org.) Direito da Regularização Fundiária Urbana Sustentável: pesquisa, teoria e prática sobre a Lei Federal № 13.465/2017. Belo Horizonte: Editar, 2018, pp. 53 a 77. 